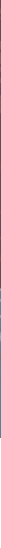

\title{
How is learning time organised in primary and secondary education?
}

- The number and length of school holidays differs significantly across OECD countries, meaning the number of instructional days in primary and secondary education ranges from 162 days a year in France to more than $\mathbf{2 0 0}$ days in Israel and Japan.

- The higher the level of education, the greater the number of instructional hours per school day. Students in OECD countries are expected to receive on average 4.3 hours of instruction per day in primary school, rising to 5.2 hours in upper secondary school.

- On average across OECD countries, around half of primary schools' compulsory curricular time is focused on reading, writing and literature; mathematics; and science, amounting to $\mathbf{2 . 2}$ hours per school day. In lower secondary education this falls to only 1.8 hours per day.

- There are wide variations across OECD countries in the organisation of the learning time within and outside the classroom but there has been a recent trend of increasing classroom instruction time dedicated to core subjects such as mathematics, and a reduction in the time spent doing homework outside the classroom.

The number of teaching hours and the length of the school year vary significantly across OECD countries. Compulsory instruction time refers to the amount and allocation of instruction time that almost every public school has to provide, and that almost all public-sector students must attend. While the average compulsory instruction time for primary students in OECD countries is 804 hours per year, formal requirements vary significantly between countries, ranging from less than 650 hours in Finland, Hungary, Korea, Latvia, Poland and the Russian Federation to 1000 hours in Australia and Colombia.

On average, compulsory instruction time increases with the level of education. Thus, lower secondary and upper secondary students enrolled in compulsory education receive on average 112 and 128 more hours of compulsory instruction per year respectively than primary students. In the Czech Republic, Finland, Germany, Mexico, the Russian Federation and Spain, the difference exceeds 200 hours (Figure 1).

Figure 1. Annual number of compulsory instructional hours and length of the school year, primary education (2015)

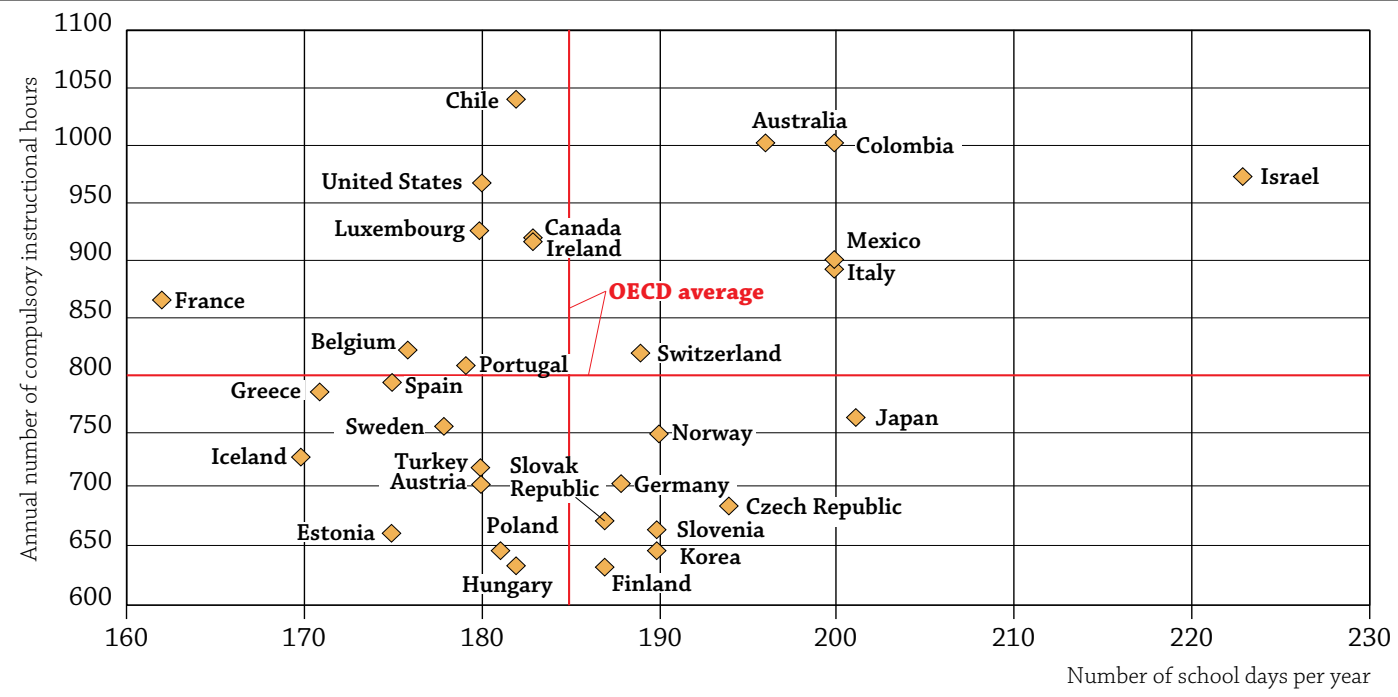

Source: OECD (2015), Education at a Glance 2015: OECD Indicators, OECD Publishing, Paris, http://dx.doi.org/10.1787/eag-2015-en, Indicator D1. 
As with compulsory instruction time, the length of the school year also varies significantly across OECD countries but there is less of a difference between primary and secondary education. On average across OECD countries, primary students receive 185 instruction days a year and secondary students 183 days. However, students in France (at primary and lower secondary), Greece (lower secondary), Iceland (primary and lower secondary), Ireland (lower secondary), Latvia (primary), Luxembourg (lower secondary) and the Russian Federation (primary) attend 170 instruction days or fewer per year. In contrast, primary and lower secondary school students in Brazil, Colombia, Israel, Italy, Japan and Mexico attend at least 200 instruction days per year.

The difference in the number of instruction days is due to variations between countries in the number and length of school holidays. For example, the length of the summer holidays in European countries varies from 6 weeks in some German Länder, the Netherlands and the United Kingdom to up to 13 weeks in Italy, Latvia and Turkey. The summer holidays are usually shorter in those countries where students have more frequent and longer holidays during the school year.

Schools' instruction hours and days are generally decided centrally, while schools predominantly decide how instruction is organised.

Countries usually have statutory or regulatory requirements regarding the hours of instruction and the number of days of school. While in at least 70\% of countries, schools decide how instruction is organised (assessment of students' regular work, assistance to students, teaching methods, grouping of students, choice of software and textbooks), decisions about instruction time are more often made at the state or central level (in 24 out of 37 countries with available data). Even among the 13 countries where decisions on instruction time are taken at the local or school level, in 11 this is within a centrally established framework. Only in England (United Kingdom) and Indonesia do schools decide instruction time completely autonomously.

The higher the level of education, the greater the number of instruction hours per day.

The length of the school day can have an impact on students' learning, especially those who are experiencing difficulties with their education. Too long a school day may leave struggling students little time to catch up, whereas the same workload distributed over more days offers greater flexibility over how the school day is organised, enabling individual support sessions to be given at more suitable times. The number of compulsory instructional hours per school day increases significantly with the level of education in most countries. On average across OECD countries, students attend 4.3 hours of instruction per day in primary school, 5.0 hours per day in lower secondary school and 5.2 hours per day in upper secondary school.

Figure 2. Compulsory instruction time per subject in primary education, in hours per school day (2015)

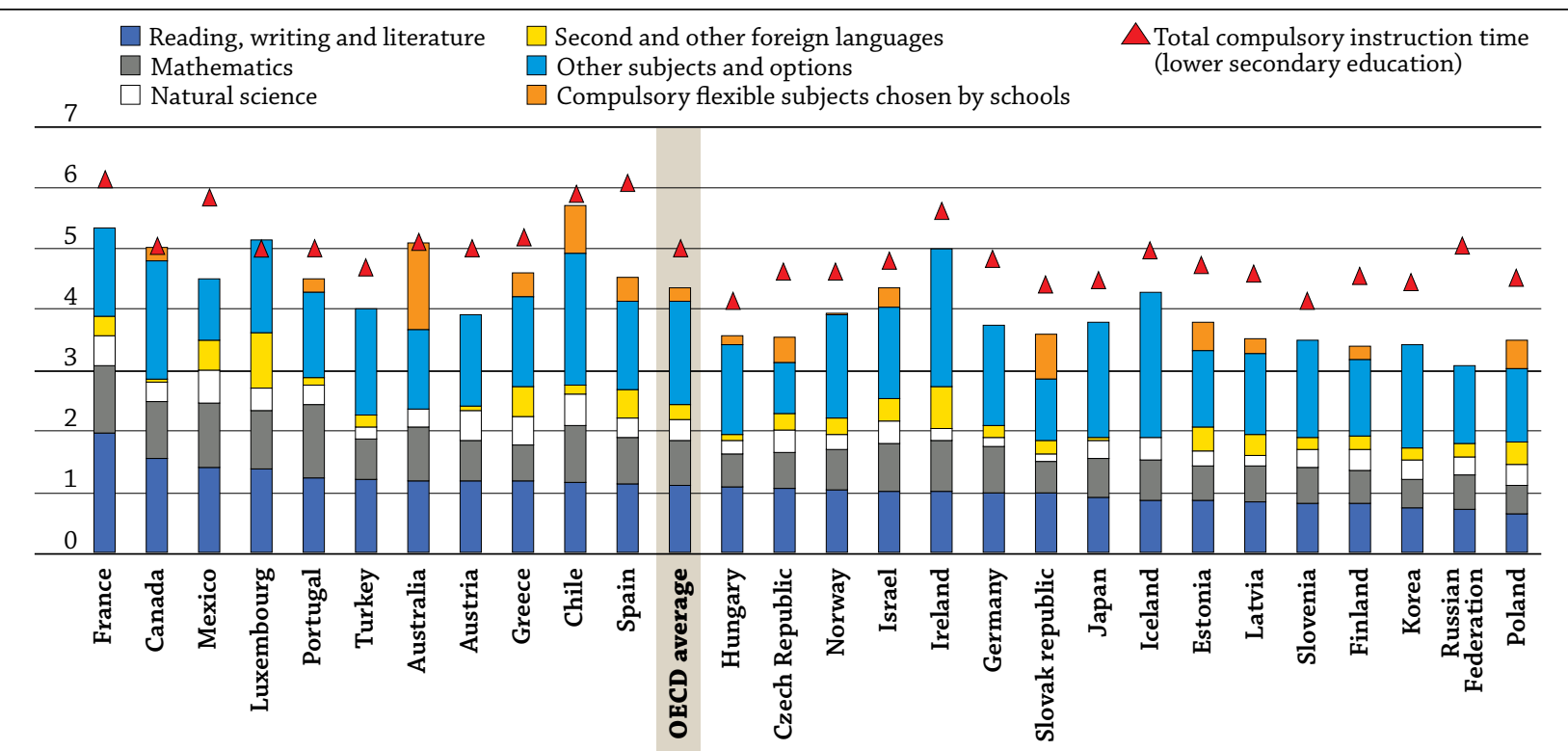

Note: Countries are ranked in descending order of the number of compulsory instruction hours (per school day) in reading, writing and literature. Source: OECD (2015), Education at a Glance 2015: OECD Indicators, OECD Publishing, Paris, http://dx.doi.org/10.1787/eag-2015-en, Indicator D1. 
In all countries except Luxembourg, the number of instruction hours per school day is higher in lower secondary than in primary education and ranges from 4.1 hours per day in Hungary and Slovenia to 6 or more hours in Colombia, France and Spain (Figure 2).

Reading, writing and literature, combined with mathematics and science, dominate the primary curriculum but foreign languages, science and social studies become more important at lower secondary. The organisation of the school year and the time devoted to subjects in the primary and lower secondary curriculum varies across OECD countries but some patterns can be detected. In primary education, around $50 \%$ of compulsory curricular time (or 2.2 hours per school day) is focused on reading, writing and literature; mathematics; and science. Reading, writing and literature is the subject given the most priority in primary education. Over 1.3 hours per school day is spent on this subject in France (2 hours), Canada (1.5 hours), Luxembourg (1.4 hours) and Mexico (1.4 hours) (Figure 2).

At the lower secondary level and later at the upper secondary level, the subject emphasis begins to change. For example, while the average time spent on reading, writing and literature falls from $25 \%$ to $14 \%$ of the school day (from 1.1 hours to 41 minutes) between primary and lower secondary education, the time spent on modern foreign languages increases from $6 \%$ to $13 \%$ (from 16 minutes to 38 minutes).

Classroom instruction time forms only part of the time students spend learning, with after-school study activities relatively well developed in most countries.

Compulsory instruction time can differ from actual instruction time as it only captures the time spent by students in formal classroom settings. In fact, instruction also occurs outside the classroom and/or school. In all countries with available data, secondary school students have homework and can participate in after-school lessons in the form of remedial "catch-up" classes or enrichment courses, with individual tutors or in group lessons provided by school teachers, or in other independent courses. These lessons can be financed through public funds or by families.

Across OECD countries, 15-year-old students reported spending 4.9 hours per week on homework or other study set by their teacher. Of this time, 1.3 hours are spent with another person overseeing the study and providing help if necessary, either at school or elsewhere. Fifteen-year-olds also reported spending 39 minutes per week working with a personal tutor, and 37 minutes per week attending after-school classes organised by a commercial company and paid for by their parents (Figure 3).

Figure 3. Average time (in minutes per week) that 15-year-old students spend each week on after-school study activities, all school subjects combined (PISA 2012)

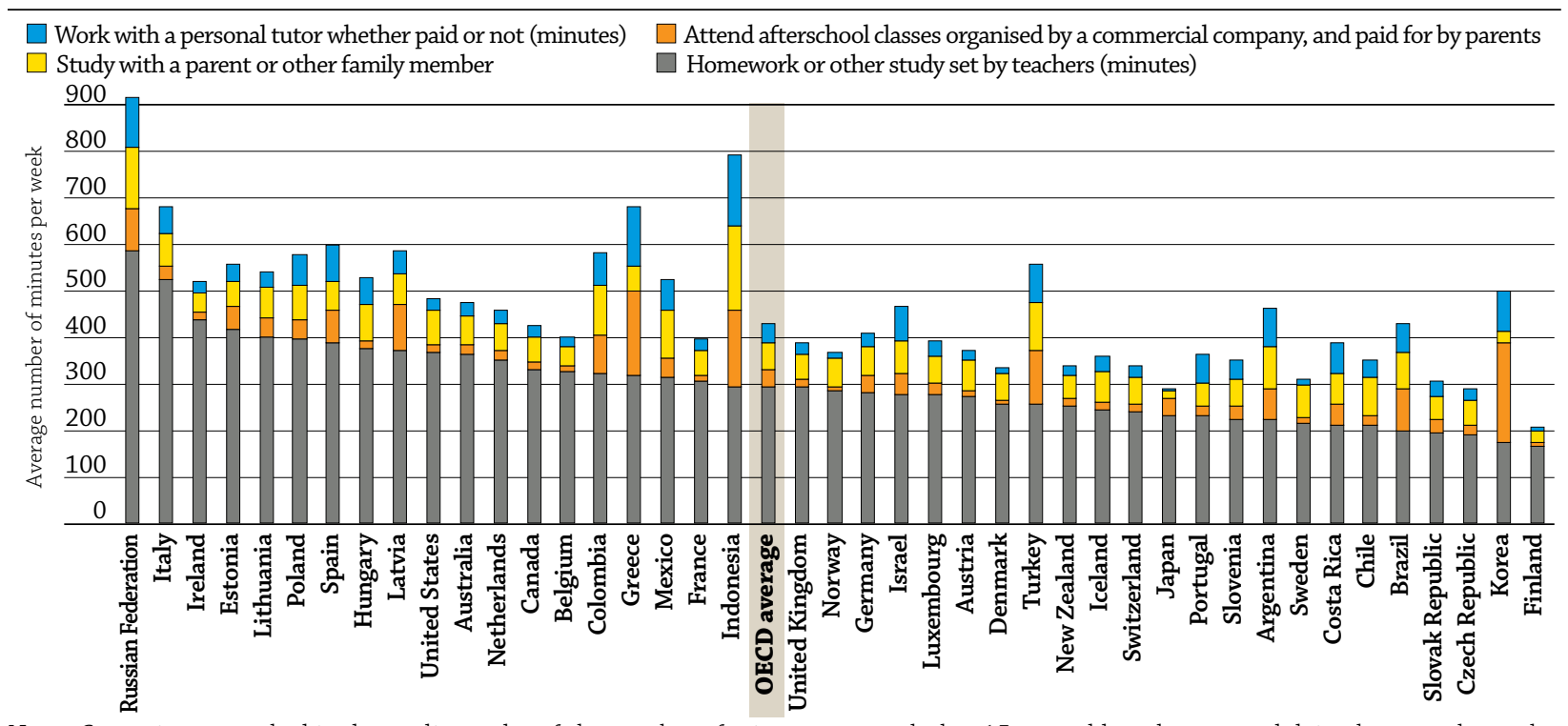

Note: Countries are ranked in descending order of the number of minutes per week that 15 -year-old students spend doing homework or other study set by their teacher.

Source: OECD (2013), PISA 2012 Results: What Makes Schools Successful (Volume IV): Resources, Policies and Practices, PISA, OECD Publishing, Paris, http://dx.doi.org/10.1787/9789264201156-en. 


\section{EDUCATION INDICATORS IN FOCUS}

education data education evidence education policy education analysis education statistics

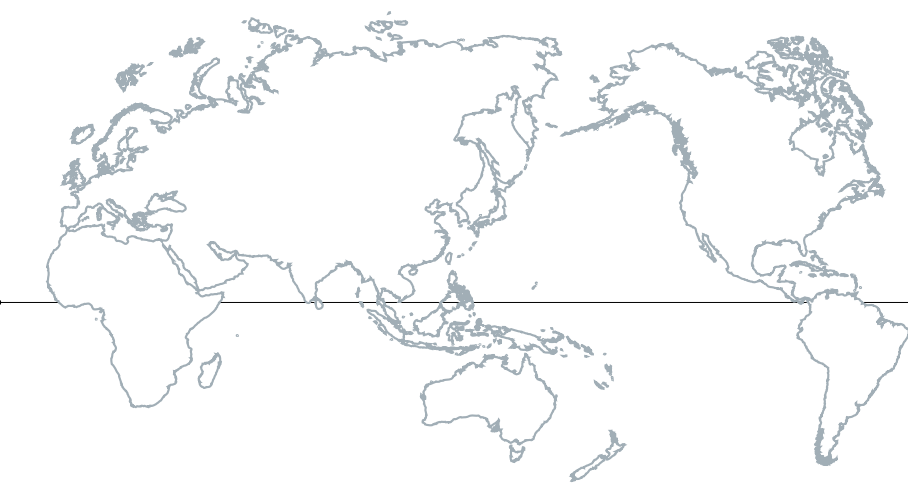

The time students spend doing homework or other study set by teachers varies between schools. However, on average across OECD countries, students attending socio-economically advantaged schools tend to spend two more hours per week on this than students attending disadvantaged schools.

The issue of instructional time is complex, with many facets determining the quantity and quality of education it provides.

The time spent in school is, in fact, much less important than how the available time is spent and on which field of education, how motivated students are to achieve, how strong the curriculum is and how good the teachers are. OECD countries set the amount and distribution of instruction time in very different ways, although recent trends have reinforced the importance given to core subjects within classrooms. For example, data from the Programme for International Student Assessment (PISA) reveal an increase in classroom instruction time in core subjects between 2003 and 2012, and a reduction in the time students spent doing homework outside the classroom. For example, across OECD countries, 15-year-old students spent an average of 13 more minutes per week in mathematics classes in 2012, while the time they reported spending on homework or other study set by teachers fell from 5.9 hours per week in 2003 to 4.9 hours in 2012.

The bottom line: The number of instructional hours students are expected to receive during compulsory education and the length of the school year vary significantly between countries but in general the higher the level of education, the greater the number of instruction hours per school day. In many countries, primary and secondary students have homework to do and can participate in after-school lessons to complement their learning time. Matching resources with students' needs and making optimal use of time are central to education policy but the wide variation across OECD countries in the organisation of the learning time within and outside the classroom suggests that countries have not worked out what the evidence says about the most effective use of students' time.

\section{For more information:}

Eurydice (2014), Organisation of School Time in Europe: Primary and Secondary General Education: 2014/15 School Year, European Commission, http://eacea. ec.europa.eu/education/eurydice/documents/facts_and_figures/school_calendar_EN.pdf.

OECD (2015), Education at a Glance 2015: OECD Indicators, OECD Publishing, Paris, http://dx.doi.org/10.1787/eag-2015-en.

OECD (2013), PISA 2012 Results: What Makes Schools Successful (Volume IV): Resources, Policies and Practices, PISA, OECD Publishing, Paris, http://dx.doi. org/10.1787/9789264201156-en.

\section{Contact}

Eric Charbonnier (Eric.Charbonnier@oecd.org)

\section{Visit}

www.oecd.org/edu/eag.htm

Education Indicators in Focus (previous issues)

PISA in Focus

Teaching in Focus

\section{Next topic:}

The internationalisation of doctorates and master's studies

Photo credit: @ Ghislain \& Marie David de Lossy/Cultura/Getty Images

This paper is published under the responsibility of the Secretary-General of the OECD. The opinions expressed and arguments employed herein do not necessarily reflect the official views of OECD member countries.

This document and any map included herein are without prejudice to the status of or sovereignty over any territory, to the delimitation of international frontiers and boundaries and to the name of any territory, city or area.

The statistical data for Israel are supplied by and under the responsibility of the relevant Israeli authorities. The use of such data by the OECD is without prejudice to the status of the Golan Heights, East Jerusalem and Israeli settlements in the West Bank under the terms of international law. 